\title{
EVOLUTION OF THE THEORETICAL FOUNDATIONS FOR MARKETING IN THE CONTEXT OF THE NEW ECONOMY FORMATION Nataliya G. Larkina ${ }^{1}$, Georgi V. Ovcharenko ${ }^{2}$, Alexei V. Tagaev ${ }^{3}$
}

\begin{abstract}
New paradigms affect major economic patterns and categories. This article discusses the semantic meaning of the evolution of marketing under the direction of socio-ecological processes in a new economy and grounds new understanding of the function of marketing. Authors provide a number of statements considering different views on the marketing essence, its ideas, and purpose. Moreover, the article describes a new approach to the specifics of innovative marketing in a neoinformation society in a new economy. Authors give clear examples of innovative marketing in the context of a certain company and industry. The study concludes that the evolution of marketing indicates the real need for the development and creation of innovative marketing NEO-tools to determine the noo-sphere development of society.
\end{abstract}

JEL Classification Numbers: E60, M31, O11; DOI: http://dx.doi.org/10.12955/cbup.v6.1171

Keywords: evolution, innovative marketing, ecological ethics, mission, innovative image, neo-information technologies.

\section{Introduction}

The evolution of the theory of marketing is the result of the analysis of marketing practice in the context of social and organizational development of new relations in the world community under its improvement.

The concept of marketing is to create satisfaction with human needs or, as P. Drucker (2004) notes, "to create and capture the consumer". On this basis, the elaboration of the theory and substantiation of marketing methods is set. Thus, marketing is considered as a managerial concept by Ph. Kotler (1991), and as a complex of actions related to the market and a way of thinking, according to Drucker (2004).

Studies of modern scientists from different countries show that innovative transformations determine not only the growth of labor productivity, but also the vector of the social and innovative development of a society, according to the theory of Kondratiev waves from the Russian scientist N.D. Kondratiev.

Thus, the core driver of innovative development of a new society is the transition of the economy to the $6^{\text {th }}$ technological paradigm, that is, the formation of a model of novation growth based on innovative technologies at all stages of the reproductive innovation cycle, as nanotechnologies determine the innovative development of organizations with orientation to the future needs of society. According to the Strategy of innovative development of Russia until 2020, such an innovative approach predetermines not only the creation of innovation policies of the state and regions, but also the formation of the country's scientific innovation system (SIS) for the transition of all industries in all regions to the $5^{\text {th }}$ and $6^{\text {th }}$ technological paradigms, which will allow for the introduction of domestic novelties into production.

\section{Scientific and technological inventions}

Kondratiev (1989) paid attention to the following: "Scientific and technological inventions can remain ineffective until the necessary economic conditions for their implementation appear".

However, the innovation motivation for the implementation of each novelty in the organization in a time interval should be simultaneously created, which will increase the country's innovative potential not only by developing domestic demand, but also by paramount access to external demand outpacing competitors - exports - and excess profit which determines the innovative activity of the country.

Such an example is Japan. Since the 1970s Japanese companies have been developing and creating their own innovative programs and service products and hence outpacing American firms. They have become the leading innovators in promising industries: biotechnology, geoengineering, laser links, that is, the life cycle of innovative service products has been shortened.

\footnotetext{
${ }^{1}$ Department of Marketing and Communications in Business at Southern Federal University, Rostov-on-Don, Russia, nat1-1a@yandex.ru

${ }^{2}$ Department of Management, the South-Russian Institute of Management of Russian Presidential Academy of National Economy and Public Administration (SRIM RANEPA/Institute), Rostov-on-Don, Russia, menedjment@uriu.ranepa.ru

${ }^{3}$ Department of Management, the South-Russian Institute of Management of Russian Presidential Academy of National Economy and Public Administration (SRIM RANEPA/Institute), Rostov-on-Don, Russia, tagaevav@uriu.ranepa.ru
} 
Scientific special knowledge and neo-technologies define not only the innovative direction of socioeconomic processes, but also the creation of innovative methods of organization and their innovative management on implementing intelligent technologies, including ones that do not include people.

In the context of globalization of the economic crisis it is very important to realize that with the growing innovative orientation of social aspects, as well as "strengthening of the technical and technological realization of scientific ideas and the increase in the economic feasibility of innovations, innovation management acquires the characteristics of an important socio-economic institution that influences various spheres of human activity, since the technological process developing in the form of revolutionary precipitous variation is combined with evolutionary social and organizationalmanagerial novelties" - Ogoleva (2010).

The development of a scientific thought under such understanding determines the change of scientific paradigms of management in the transition of the economy to the 6th technological paradigm, which contributes to the emergence of various types of new special knowledge in the innovation sphere that functions only when innovators, investors and commodity producers interact.

However, it should be noted that instant changes in technology determine the time aspect of the development and the introduction of novelties in production at all stages of the innovation cycle in which parallel-consecutive development sub-cycles occur.

Toffler (2004) notes in his studies that fundamental research in particular benefits technology development by means of the creation and transfer of knowledge, skills and tools, the network of professional contacts and also the creation and transfer of ready-to-use written information.

When developing and implementing innovations in manufacturing, the model of the nonlinear innovation process is implemented as the transformation of scientific and technological knowledge into the sphere of customer satisfaction. The process of commercialization in its turn is determined by the creative interaction of the state and the regions, since the implementation of innovation projects in the contemporary economy is conducted simultaneously in different industries based on digital information technologies. These technologies determine the development of an innovative idea by means of the tools of innovative marketing, taking into account the analysis and evaluation of research on the demand in the market environment by means of neuro-modeling.

The Japanese economist Conno (1987) outlined four sources of innovative ideas: market needs, the opportunities of science, companies' needs and policies, and the imitation of existing companies.

In practice, the vector of innovative development of the modern economy is characterized by hypercompetition, which predetermines the definition of a new innovative marketing strategy by the leaders of innovative organizations to capture the secret needs of specific customers who want to buy an innovative service product.

According to Twiss (1989), "we are dealing with significant changes in the developer's ideas on the nature of the transformation of his scientific and technical potential into business purposes, since the second approach is oriented to the needs of the possible consumer. More agreement on the views between the developer and the sales manager is needed than the one achieved by many companies, and the achievement of this coincidence may require appropriate organizational changes".

\section{Innovative marketing in Russia}

At the same time, it should be noted that the concept of innovative marketing is emerging in Russia as a new research area determined not only by the need of the state regulation of the innovation sphere, but also by the creation of a national innovation system both in the state and in the regions. The creation and implementation of models of innovative marketing are predetermined by the instantaneous change of neo-technologies and neo-information technologies in the course of developing and creating innovative goods and services. These technologies determine social orientation of innovative marketing:

- humanity - a creative person;

- ecological ethics - conservation of nature;

- information technologies - improving people's lives.

The specifics of the development of the concept of marketing with the transition to innovation was determined by the evolution of the economic activity of society to the level of a neo-informational 
society in which all interact: countries, companies, territories and public organizations, taking into account the cyclical development, according to the theory of the Russian scientist Kondratiev and the shift of technological paradigms, which predetermined changes in the focus (stages) of marketing.

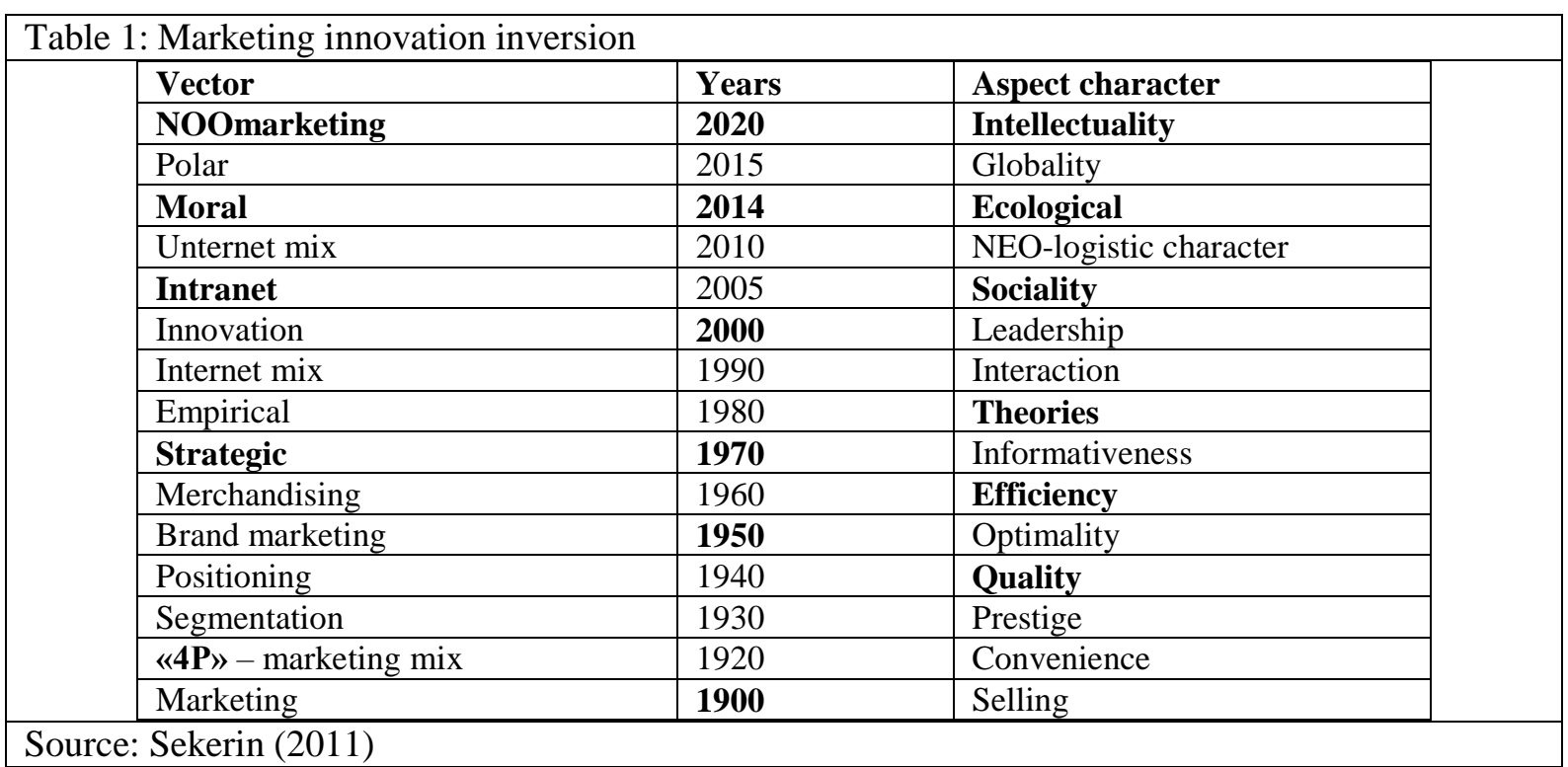

The focus of marketing is as follows: the organization becoming the leader is the one that can create a novelty determining not only the usefulness of the product for a particular client, but also the innovative significance of the organization.

Example: The LLC "Combine plant Rostselmash" that designs the innovative models of combines, taking into account the future wishes of customers, and hence creates value for the organization and an innovative image for society. Thus, it finds the application of innovative models of marketing as a socio-ethical aspect, since the foresight focus of marketing was predetermined not only by the evolution of an information society, but also by the specifics of changing models and levels of management, taking into account the emergence of hyper-competition and changes in the balance of the market environment. The changes determine the evolution of marketing and the mission - the reason for the existence of organizations to meet the changing needs of the neo-society (Figure 1).

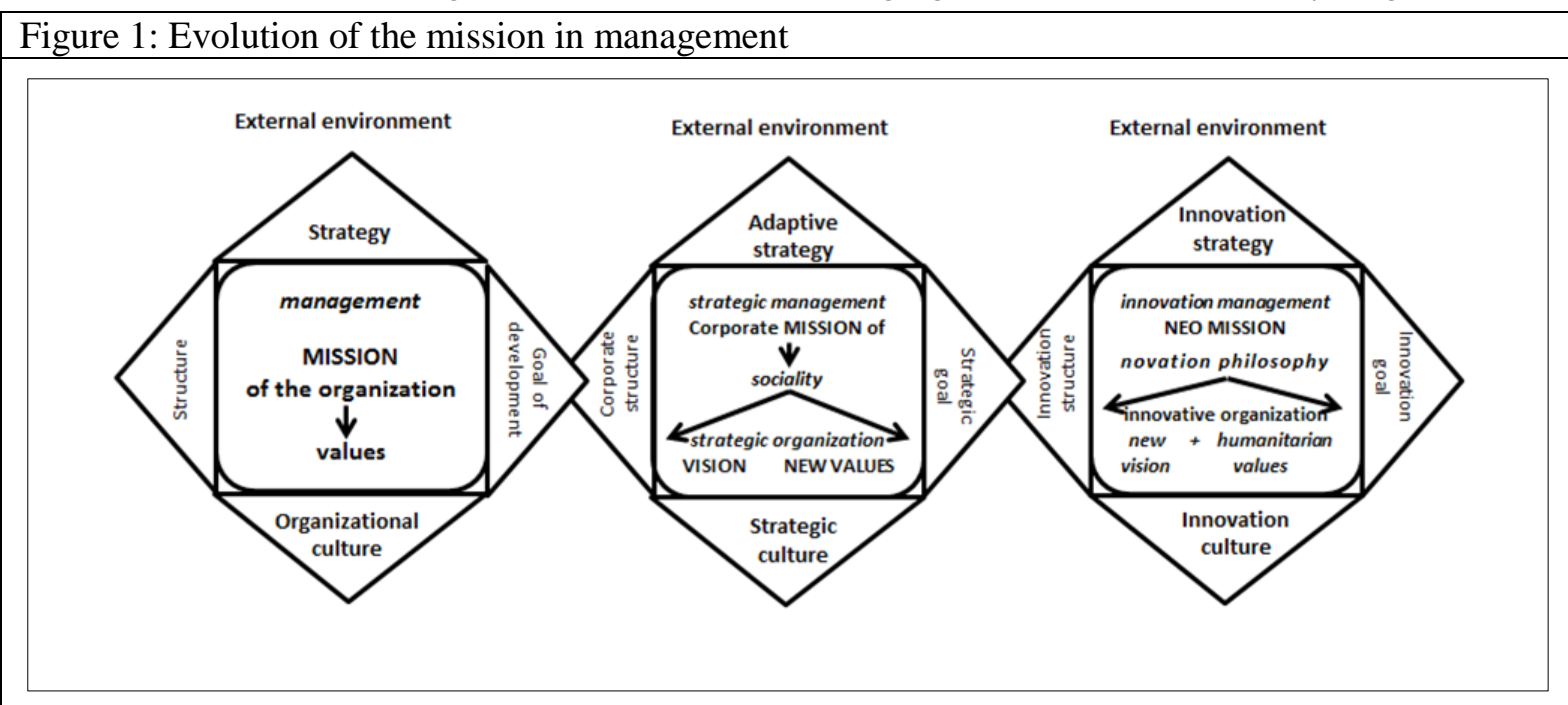

Source: Authors

The medium-term crisis in the global economy predetermines the use of functions of innovative marketing - the creation of new ideas based on the innovative thinking of managers, taking into account the future desires of particular clients. Kotler and Trias de Bes (2004) note in their works that lateral marketing emerged inside the company OMRON Electronics. This is a vivid example of an innovative approach in marketing to the creation of the "model for predicting the future of 
technology" and hence was named SINIC (an abbreviation for, innovation, need, impetus, cycle, "from grain-innovation to impetus-needs"). The goal of SINIC was to predict how far the market will need high-tech products in the future and to implement flexible strategic planning on this basis. The authors of this theory revealed ten major "innovative shifts" in the history of mankind, each of them having laid the foundation of society of a certain type: primitive, collective, agrarian, craft, and industrial. Having overcome the stage of mechanization and then automation, humanity entered the era of cybernetics in 1974, according to the authors of the model. The remaining years before the beginning of this milestone will be the "golden" time of computer science and cybernetics. It is not difficult to assess the importance of this conclusion for the long-term marketing strategy of OMRON Electronics. The company with this approach is constantly focused on anticipating the needs of society.

As the president of this company Tateisi remarked, they implemented the theory of social inquiries in their activity, that is, they create goods that will find their way to the consumer themselves.

So, a modern innovation marketing manager is a creator and innovator obsessed by the spirit of creative entrepreneurship with a social and environmental intention in his activity (Ovcharenko et al, 2014).

In practice, innovative marketing tools determine the interaction vector on the demand of target groups and the potential consumer of innovative products with a flexible response to rapid changes in the desires of customers and the demand in the market environment. This response entails the ability of an innovation marketing manager to discover what innovation to create in order to determine new niches of demand and whether the client is ready to pay for it. It determines the vector of innovative ideas (Figure 2) corresponding to changes in the speed of information technology and the customer "taste".

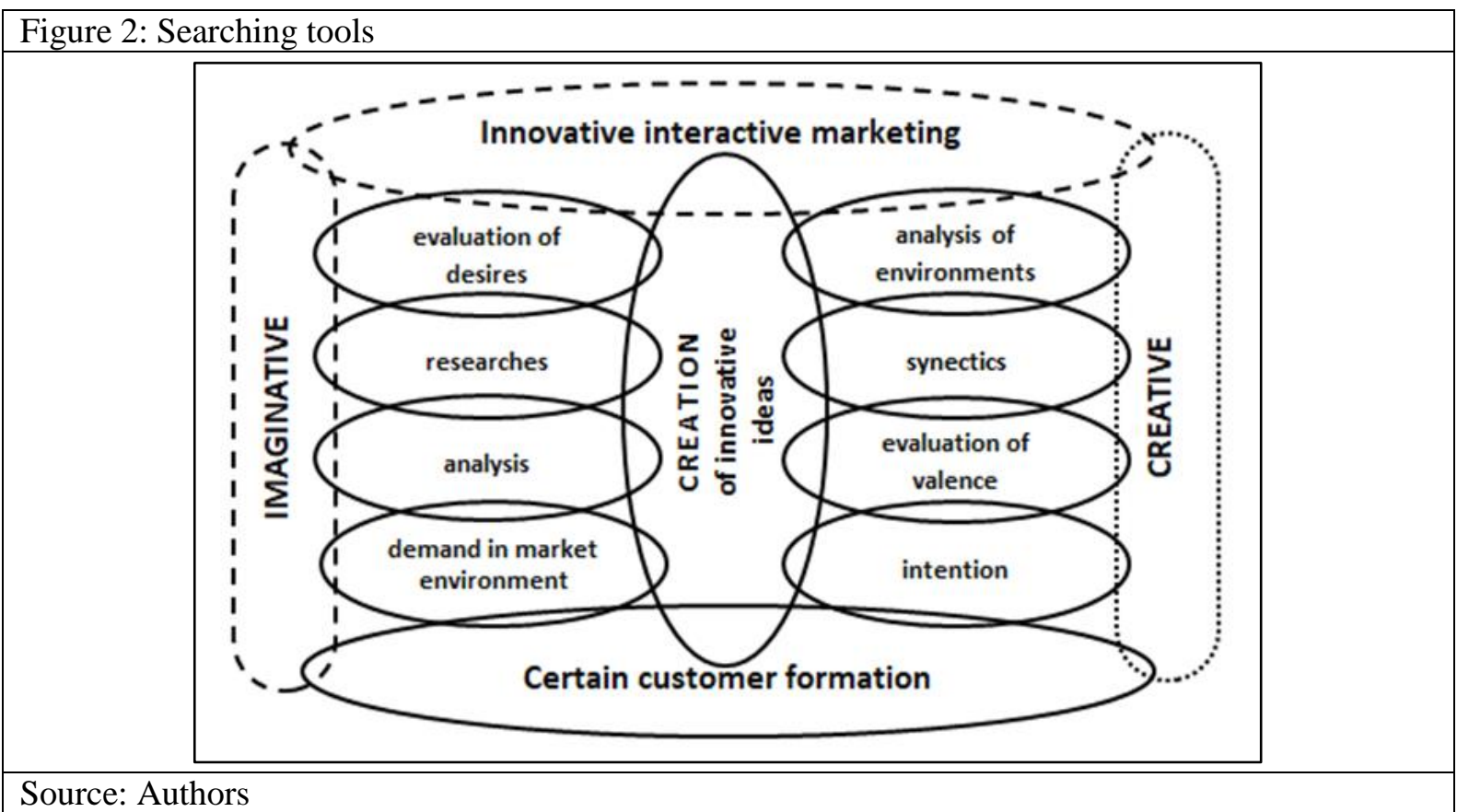

The relevance of this approach is weighed with the intention of the innovation marketing manager: accuracy of demand analysis; focus - direct dialogue; catching the emotions of customers; foresight of the changes in NEO-technologies, which will allow determining the elasticity of demand for innovative goods (services) (Ovcharenko and Larkina, 2016).

In practice, the senior management is obliged to apply mathematical modeling in the activity of an innovative organization developed by Soviet economists (10 years earlier than in the West) to measure and forecast the environment. Mathematical modeling is based on neuro-modeling in the field of psychometry and the utility theory when creating innovative products or services in various types of activities, taking into account special tables by the stages of the life cycle of the innovative product. It will allow not only determining the vector of innovation activity, but also understanding psychodemographic micro-segmentation of the niche (AUP, 2018). 
Innovative marketing research shows that the analysis of socio-psychological characteristics of target consumers of innovation is necessary, since it helps to choose the most profitable set of consumer properties of innovative products or services, and the optimal correlation between the price and the quality of innovative products (Johnson et al, 2002).

One of the determining factors to catch changes in the desires of customers should be the search of criteria conducted by innovative marketing for the making of an innovative decision by the senior management of the organization to develop and create the necessary innovative product or service, that is, the task is to create an innovative image that facilitates the change in thinking of customers for the purchase of this particular product - this is the aspect of practical branding which determines the ideology of client's rational choice of what he wants to buy.

The senior management in practical activities of innovative organizations is obliged to constantly conduct an analysis of the criteria by each innovation in order to be confident in understanding of the future desires of customers, which will contribute to macro- and micro-segmentation of the innovative product or service, taking into account the changing needs of the NEO-community.

The logical analysis of the success of the innovative product implementation demonstrates that the competitive advantage is to be a leader determined by thin and flexible forecasting of not only the competitive situation, but also changes in the demand of the environment, taking into account:

1. strategies of competitors;

2. goals that can really be achieved (Kevorkov and Leontiev, 1999),

3. that is, be able to determine its position in this situation aspects:

4. the reliability in operation;

5. flexible pricing strategy;

6. quality of the world standard;

7. innovative image;

8. service perceived by the client.

\section{Innovative positioning}

This scientific approach to the client determines innovative positioning, taking into account the specifics of the clients' traditions, that is, to reach an understanding that the innovative service is unique and almost ideal considering the desired design - offers the customer the hope for a taste.

In the conditions of the global crisis economy when the new economy is being created in Russia, to be an innovative leader it is necessary to constantly monitor demand and to choose valency on the basis of:

- the ability of marketers in innovations to identify new customer preferences;

- the degree of novelty of the created innovative service product;

- the definition of the niche of innovative positioning;

- the subtle analysis of competitors' strategy (Guide for managers of innovative SMEs).

Simultaneously, innovation marketing managers should analyze the exhibition process, as well as conduct research on fairs, using Internet networks with the use of virtual media.

A fair is an organized market of various goods functioning from time to time as one of the organizational measures to promote the product, in which the demonstration of the goods is combined with its sale. Fairs give an opportunity for a wide range of manufacturers, consumers, intermediaries to enter into direct commercial mutually and advantageous contacts which help to regulate supply and demand, intensify the economic initiative of the parties, while taking into account partner trust. Fairs give the real opportunity of offering a new product, the reliability of its manufacturer, its image, and the level of maintenance. First of all, fairs establish information contacts. The results of the fair's activities allow manufacturers to make decisions about the release of new products, their offering (Innovative activity of a small enterprise).

In terms of theory this moment is presented in the studies of Russian scientists with the practical development of "goods tested by experience" in the implementation of the aspect - the export of innovation for specialized exhibitions in regions and abroad. It includes the transfer of a new combine model for exploitation in the form of a preferential sale, which allows developing a new niche by personal work with clients that determine the recommendation of the innovative model for distribution 
in the regions of Russia (LLC "Combine plant Rostselmash") (Ovcharenko and Larkina, 2017).

As Sekerin (2011) notes, the strategy of selling new products should determine the best combination of work with end users, retail trade, sales agents and wholesalers. Therefore, one of the key issues of sale is the choice of the optimal path by which the goods move from the producer to the consumer, or the distribution channel.

However, the authors note that before creating their own dealer network, it is necessary to first determine the list of regions in which it would be expedient to open dealer centers and then determine the procedure of establishing relationships between them and the enterprise. It is recommended to choose those regions where the demand for products is sufficiently stable, or those where the organizations are to fulfill the task of pressuring competitors. If the product requires the organization of service, the choice may be related to the convenience of the geographic location of the dealer and the service center for consumers from neighboring regions.

The practice of the company's senior management in the successful development and creation of novelties in production is characterized by the strategic risk which is determined by the degree of novelty of innovative products or services and levels:

1. a market and a technology are known - a minimum level of risk, as the company relies on its competence;

2. a new market, but a known technology - the risk is mostly commercial and depends on technological innovations;

3. a market is known, but a technology is new - the risk is more technical and it is determined by technological innovations;

4. a new market and a new technology - the maximum level of risk associated with the summation of all risks (Wilson, 2003).

Studies show that the level of failure of new products recently introduced to the market ranges from $33 \%$ to $35 \%$. The survey of 138 firms carried out by the Association of National Advertises provided the following results: $27 \%$ of the expansion of the existing range, $31 \%$ of brand innovations and $46 \%$ of the new products fail. This data characterizes the problem under consideration only partially, since many projects are rejected at the stage of preliminary assessment as a result of a shortage of funds, ideas and time. The risk is aggravated by the fact that due to the significant influence of technological changes, the life cycle of new products is reduced.

The practice of the leading Japanese companies shows that successful customer service can be the most important feature that distinguishes an innovative firm from its competitors. There are three main categories of service elements: pre-sale, sale and after-sale. After-sale service includes: installation of products, warranty service, provision of spare parts, temporary replacement of goods, receipt and replacement of defective products (Nonaka and Takeuchi, 2011).

Thus, the implementation of innovative marketing tools is the effective promotion of innovation to meet the changing needs of society.

At the same time, the logistics of the success of an innovative product, especially when developing it, determines the need to implement special measures for maintenance and service:

- speed of service;

- reliability in operation, taking into account the life cycle of the service product;

- cost of maintenance;

- integration of diagnostic systems;

- remote management of dealer centers.

Example: The LLC "Combine plant Rostselmash" raised the service of combines to the world class level and is outpacing competitors with an innovative demand, creating a new philosophy of clients with a social orientation of partner relationships.

The development of the global crisis economy and society is determined by the emergence of: new knowledge, information and communication technologies. They determine the formation of an innovative and information economy, taking into account the specifics of the Internet, which allows innovation marketing managers to determine not only the vector of ideas, but also true NEOinformation. True NEO-information is the basis for innovative activity of organizations for the 
implementation of innovative ideas in production in the form of a novelty, its commercialization being an innovative product or service.

\section{New economy formation in Russia}

In the context of the formation of the new economy, various Russian companies started to conduct work on the Internet however, due to the lack of clear recommendations and proven methods of Internet technologies, inconsistency of innovative projects with strategic goals and/or organization's possibilities, Internet projects often fail, and not only because of the lack of a methodology, but qualified specialists in the field of Internet technologies implementation as well. However, it should be noted that the Internet presents unique opportunities for analyzing the activities of competitors, which results from the features of working in an interactive environment and allows organizations not only to successfully use the Network to monitor competitors' strategies, but also to neutralize advances by analyzing the current situation, which makes it possible to forecast the future innovation development.

As the experience of Western countries shows, where e-business determines flexible work using the Internet as a tool for shaping the demand for innovation, determining the synergetic effect, especially when choosing the target geographic niche with the creation of the emotional impact on the client, which determines the innovative image of the organization in society.

However, the logic of the life cycle of an innovative product is determined by the community's awareness of its usefulness, taking into account the psychological and social aspects, when the leaders of the innovation organization understand that customers change the criteria for valuing values in a time interval. Therefore, the moment the innovative product is sold to the first potential client is of paramount importance for the success of the organization in innovation because of rapidly changing demands - the emergence of new needs in society, which determines the subtle information about the customers, that is, the client must be a partner.

So, the innovative marketing of values is the highest level of its evolution with orientation only to the emotions of a concrete client - the creator of his own novation values.

So, the peculiarity of Japanese marketing is based on three key elements - the unconditional priority of the consumer, information technologies and entrepreneurial spirit which stimulates creativity.

Hertig notes in his research that the development of marketing in Japan is characterized by aspects:

- 1946-1953 - Japanese enterprises are focused on importing technologies from their developed countries and improving the image of goods;

- 1954-1964 - conducting marketing research and implementation of the product policy;

- 1965-1969 - application of marketing tools in the field of diversification of product lines;

- 1970-1980 - following the social responsibility of marketing;

- 1981-1990 - development of marketing strategies - a marketing mix and international recognition of the competitiveness of Japanese firms are formed;

- 1991-2010 - a mature marketing philosophy that determines domestic demand (Crosby et al, 2003), that is, the penetration of marketing into all functional levels of the organization on the basis of a creative management style that defines the basic principles:

○ the priority should be given to a client;

○ information technologies;

○ creative work.

As Lawrence Crosby underlines in one of the last publications in the journal of Marketing Management, we can never fully understand the mystery of consumer behavior, but modern methods used for their intended purpose can make today's marketing managers Sherlock Holmes rather than simpletons entangled in paperbacks.

\section{Conclusion}

Information marketing technologies that allow analyzing the movement of goods from the manufacturer to the end user in real time and also reacting instantly to any inquiries of the consumer, determine the focus of marketing with flexible and ready-to-change customer preferences using the elements of the insight, catching the secret desires, defining the priorities in the activity of marketing managers: information technologies; ecology; foresight - insight; client satisfaction; man - value; creativity; innovations; leadership; sensibility. 
Thus, the study of the evolution of marketing shows the need for the development and creation of innovative marketing NEO-tools that determine the noo-sphere development of society in the implementation of space technologies by human neuro-intelligence.

The material is reconciled, figures, facts, quotes are checked in the primary source. The material does not contain information for restricted distribution.

\section{References}

AUP. (2018). Administrative and managerial business-portal. Available at: http://www.aup.ru

Conno, T. (1987). Strategy and structure of Japanese enterprises. Moscow: Progress, 383 p.

Crosby, A. L., Johnson, S. L., Winslow, D. K. (2003).Chasing the Elusive customer. Marketing Management, July/August.

Drucker, P. (2004). The effective executive. Moscow: Astrel, AST, Ermak, 288 p.

E-library of entrepreneurship. Guide for managers of innovative SMEs. [Online]. Available at: http://www.rcsme.ru

Johnson, J., Wood, D., Wardlow, F. (2002). Contemporary Logistics. Moscow: Williams, 624 p.

Kevorkov, V.V., Leontiev, S.V. (1999). Policies and practices of marketing: teaching aids. Moscow: ISARP, "Business-

Thesaurus", $192 \mathrm{p}$.

Kondratiev, N.D. (1989). Problems of economic dynamics. Moscow: Ekonomika, 526 p.

Kotler, Ph. (1991). Fundamentals of Marketing. Moscow: Progress, 652 p.

Kotler, Ph., Trias de Bes, F. (2004). Lateral Marketing: New Techniques for Finding Breakthrough Ideas. St.-Petersburg: Neva, $192 \mathrm{p}$.

Nonaka, I., Takeuchi, H. (2011). The Knowledge-Creating Company. How Japanese Companies Create the Dynamics of Innovation. Moscow: Olymp Business JSC, 384 p.

Ogoleva, L.N. (2010). Innovative management. Moscow: INFRA-M, 238 p.

Ovcharenko, N.G., Larkina, N.G. (2016). Formation of the scientific concept of innovative marketing in the new economy. Rostov-on-Don: SRIM RANEPA/Institute, $130 \mathrm{p}$.

Ovcharenko, N.G., Larkina, N.G. (2017). Innovative management. Rostov-on-Don: SRIM RANEPA/Institute, 352 p.

Ovcharenko, N.G., Larkina, N.G., Nekrasova, V.V. (2014). Contemporary aspects of the innovative development of sociotechnical systems in the new economy. Rostov-on-Don: Donizdat, $160 \mathrm{p}$.

Portal of distance consultation of small businesses. Innovative activity of a small enterprise. [Online]. Available at: http://www.dist-cons.ru

Sekerin, V.D. (2011). Innovative marketing. Moscow: INFRA-M, 238 p.

Toffler, A. (2004). The Third Wave, Moscow: AST publ., 345 p.

Twiss, B. (1989). Managing technological innovations. Moscow: Ekonomika, 271 p.

Wilson, R. (2003). Planning Your Internet Marketing Strategy. Moscow: Grebennikov Publishing House, 261 p. 